\title{
The effect on intraocular pressure of latanoprost once or four times daily
}

Department of Clinical Science, Ophthalmology, Umeå University, SE-901 85

Umeå, Sweden

C Lindén

Department of

Neuroscience,

Ophthalmology,

Uppsala University,

SE-751 85 Uppsala,

Sweden

A Alm

Correspondence to: C Lindén, Department of Clinical Science,

Ophthalmology, Umeå

University, SE-901 85 Umeå

Sweden

christina.linden@

ophthal.umu.se

Accepted for publication 4 April 2001

\author{
Christina Lindén, Albert Alm
}

\begin{abstract}
Aims-To compare the effect on intraocular pressure (IOP) of latanoprost applied once daily with four times daily and to study if the difference persisted when treatment changed to once daily.

Methods-IOP was followed in 28 healthy volunteers in a double masked randomised 52 day study. Latanoprost 50 $\mu \mathrm{g} / \mathrm{ml}$ was administered once daily in one eye and four times daily in the other during 2 weeks. Subsequently both eyes received one daily drop for 2 weeks. After another 3 weeks without treatment, a single drop was instilled in each eye.

Results-The IOP reduction on days 2 and 3 was greater in the eyes treated with four daily doses $(p<0.01)$. During the following period there were no statistically significant differences between the eyes. After 3 weeks without treatment the IOP was lower than pretreatment $(p<0.001)$. A single dose of latanoprost on day 50 resulted in a similar decrease in IOP in both eyes. Transient photophobia, mild flare, and/or a few cells occurred in 15 subjects. Two subjects were withdrawn because of photophobia and/or signs of anterior uveitis. Conclusion-Latanoprost four times daily caused an IOP reducing effect which was similar to once daily dosing, except for the first 2 days of treatment when it was more effective. Transient photophobia, cells, and flare were common during the four dose regimen, but resolved spontaneously without cessation of treatment.

(Br f Ophthalmol 2001;85:1163-1166)
\end{abstract}

Latanoprost is a prostaglandin $\mathrm{F}_{2 \alpha}\left(\mathrm{PGF}_{2 \alpha}\right)$ analogue developed for glaucoma treatment. It has a potent ocular hypotensive effect in humans. ${ }^{1-3}$ Its main mechanism of action is on uveoscleral outflow. ${ }^{45}$

It has been shown that twice daily dosing of latanoprost has less ocular hypotensive effect than once daily. ${ }^{6-9}$ Although the initial effect on the intraocular pressure (IOP) with twice daily application is more pronounced than with once daily applications there is a loss of effect with twice daily applications during the first week. ${ }^{6}$ The mechanism behind this loss of effect is not clear, and we decided to determine if an even more frequent administration of latanoprost would result in further loss of the effect on IOP. Thus the aim of this study was to compare the effect on IOP of latanoprost applied once daily in one eye with latanoprost applied four times daily in the other eye. A secondary aim was to investigate if any difference between the two treatment arms was persisting if the treatment was changed to one daily drop and if such a difference could be recalled by a single dose of latanoprost after 3 weeks without treatment.

\section{Materials and methods}

SUBJECTS

Twenty eight healthy volunteers, 15 men and 13 women, were recruited for this study. The median age was 28 years (range 19-48). All subjects underwent a preinclusion ocular examination to ensure their eyes were normal. None of the participants used drugs on a regular basis, except contraceptives, and no drugs were allowed 2 weeks before and during the study period. Contact lenses were not allowed within 1 week before the start of the study and during the study.

\section{STUDY DESIGN}

This was a double masked randomised study. The study period was 52 days (days $0-51$ ). All IOP measurements were made at 8 am before the first instillation of drops of that day. Three replicate measurements were performed each time. The medians of the readings for each eye were recorded and used for analysis. The same daily calibrated Goldmann tonometer (HaagStreit, Bern, Switzerland) was used throughout the study. The same person performed all readings.

The study was divided into different treatment periods.

- days 0-1: no treatment was given on day 0 . Baseline IOP was defined as the mean of the median IOPs measured on day 0 and before treatment on day 1.

- days 2-14: latanoprost $50 \mu \mathrm{g} / \mathrm{ml}$ was administered four times daily ( $8 \mathrm{am}$, noon, $4 \mathrm{pm}$, and $8 \mathrm{pm}$ ) in one randomly assigned eye and once daily $(8 \mathrm{pm})$ in the other. In that eye placebo eye drops replaced the three remaining instillations. Thus, each participant received three coded bottles. The evening bottle marked "evening bottle for both eyes" contained latanoprost. The remaining two bottles, one of which contained latanoprost and the other placebo, were marked "right eye" and "left eye." They were used for the three daytime instillations. The IOP was determined on days $2-5$ and 8 .

- days 15-28: latanoprost was administered once daily $(8 \mathrm{pm})$ in both eyes. The IOP was measured on days 15,18 , and 22 .

- days 29-49: no treatment was given. The IOP was measured on day $29,32,36$, and 43. 
Table 1 Symptoms and signs of inflammation in 14 of 28 eyes treated with latanoprost four times daily. No symptoms or signs were observed in the remaining 14 eyes. Symptoms and signs were most marked on day 3 or 4 and subsided spontaneously within a week despite continuous treatment

\begin{tabular}{|c|c|c|c|c|}
\hline Subject No & Photophobia & Flare & $\begin{array}{l}\text { No of cells in a } 2 \mathrm{~mm} \text { slit } \\
\text { (no of days) }\end{array}$ & Comments \\
\hline 1 & Mild & & & \\
\hline 2 & Mild & & & \\
\hline 4 & Severe & & & $\begin{array}{l}\text { Withdrawn. Symptoms } \\
\text { resolved within } 2 \text { days }\end{array}$ \\
\hline 5 & & & 2-3 (2 days) & \\
\hline 9 & Severe & Mild & $8-10$ ( 6 days) & $\begin{array}{l}\text { Withdrawn. Signs and } \\
\text { symptoms resolved within } \\
\text { a week }\end{array}$ \\
\hline 12 & Moderate & Mild & 2 (2 days) & $\begin{array}{l}\text { Miosis. Subsides. Still } \\
\text { present on day } 8 \text {, but not } \\
\text { on day } 15\end{array}$ \\
\hline 13 & Mild & & 1 (1 day) & \\
\hline 15 & Mild & & & \\
\hline 16 & Severe & Mild & 3 (6 days) & \\
\hline 17 & Mild & & & \\
\hline 23 & Moderate & Mild & 1 (1 day) & \\
\hline 25 & Mild & Mild & & \\
\hline 26 & Mild & Mild & & \\
\hline 27 & & Mild & 1 (1 day) & \\
\hline
\end{tabular}

- days 50-51: a single dose of latanoprost was administered at $8 \mathrm{pm}$ on day 50. The IOP was measured on both days.

The time for instillation of the evening drops the day before study days was noted. A schedule deviation of more than 30 minutes was not allowed. Any symptoms or side effects during the study days were registered, as well as any event affecting the study between these days.

The study protocol followed the tenets of the Declaration of Helsinki and was reviewed and approved by the Medical Products Agency and by the ethics committee of the medical faculty of Umeå University. Informed consent was obtained from each individual.

DATA ANALYSIS AND STATISTICAL EVALUATION The difference in IOP reduction from baseline and the difference between the eyes were used as the main response variables. Student's paired two tailed $t$ test was performed to test significance of differences in IOP between the eyes. Means, standard deviations (SD), and/or $95 \%$ confidence intervals are presented. Values of $\mathrm{p}<0.05$ were considered statistically significant.

\section{Results}

Twenty six individuals completed the study per protocol. Two men were excluded on day 3 because of marked photophobia in the eye treated with four daily drops. One of them also had a slight flare and 8-10 cells in the slit at slit lamp examination. The other person had no flare and no cells. These symptoms and signs resolved within a few days after the treatment was terminated.

The mean IOP, at baseline, in the eyes receiving latanoprost once daily was $14.4 \mathrm{~mm}$ $\mathrm{Hg}$ (range 11-20, SD 2.5). The corresponding figures for the eyes treated four times daily were $14.5 \mathrm{~mm} \mathrm{Hg}$ (range 11-19, SD 2.3) $(\mathrm{p}=0.66)$. The IOP reduction from baseline is shown in Figure 1. It was statistically significant in both eyes at all time points during treatment $(\mathrm{p}<0.001)$. The IOP reduction on days 2 and 3 was significantly greater in the eyes treated with four daily doses compared

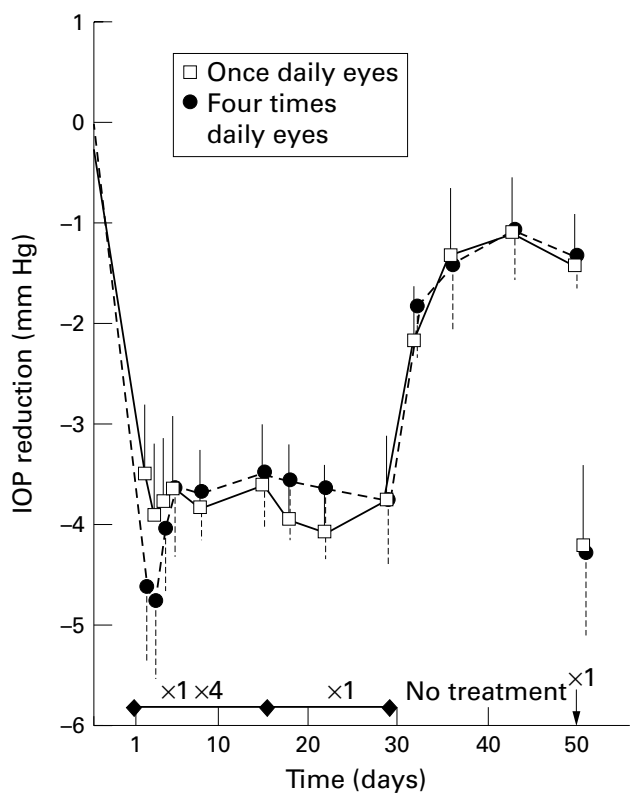

Figure 1 Mean IOP reduction with baseline as reference during treatment with latanoprost $50 \mu \mathrm{g} / \mathrm{ml}$ one or four times daily and follow up. Treatments are indicated in the lower part of the figure. Open squares represent eyes that started with once daily treatment and solid circles represent eyes that started with four times daily treatment. The IOP reduction on days 2 and 3 was significantly greater in the eyes treated with four daily doses compared with the eyes that received latanoprost once daily $(p<0.01)$. No other differences in IOP reduction between the eyes were statistically significant. Error bars denote half the $95 \%$ confidence interval $(n=26)$.

with the eyes that received latanoprost once daily $(p<0.01)$. After that time there were no statistically significant differences between the eyes. At day 15 the IOP reduction was significantly smaller in the four times daily treated eyes than at day $3(p<0.001)$. The mean IOP reduction in those eyes was $4.7 \mathrm{~mm} \mathrm{Hg}$ (SD 2.0) at day 3 and $3.4 \mathrm{~mm} \mathrm{Hg}(\mathrm{SD} 1.4)$ at day 15. For the once daily treated eyes there were no statistically significant differences. After termination of treatment on day 28 the IOP slowly increased. After 3 weeks without treatment it was still 1.4 (SD 1.2) or $1.3 \mathrm{~mm} \mathrm{Hg}$ (SD 1.0) lower than the pretreatment IOP in the eyes previously treated with latanoprost once or four times daily $(\mathrm{p}<0.001)$. After a single dose of latanoprost in both eyes in the evening of day 50 a similar decrease in IOP was seen in both eyes on day 51 .

Including the two subjects that were withdrawn from the study, 12 subjects (43\%) experienced transient photophobia in the four times daily treated eye. A mild flare and/or a few cells were observed in 10 subjects at some time(s) during the first week of treatment. In one individual it was observed only in the once daily treated eye. As can be seen in Table 1, seven of the subjects complaining of photophobia also showed signs of flare and/or cells in the anterior chamber in the eye treated with latanoprost four times daily - that is, $29 \%$ of all. Another two subjects had mild flare/cells in the four times daily treated eye, but did not complain of photophobia. In all subjects that experienced photophobia the symptoms and signs disappeared despite continuous treatment. 


\section{Discussion}

In several studies ${ }^{6-9}$ it has been found that once daily dosing of latanoprost is superior to twice daily dosing in terms of IOP reduction. It has also been shown that some of the IOP reduction with the twice daily regimen is lost within 1-4 weeks of treatment. ${ }^{9-11}$ One possible explanation is development of subsensitivity with twice, but not once, daily dosing of latanoprost. ${ }^{9}$ The aim of the present study was to test if a dosing frequency of four daily drops would result in even more loss of the efficacy.

We found that four daily doses of latanoprost reduced the IOP significantly more than one daily dose during the first 2 days in healthy volunteers. From that time point no statistically significant difference in IOP reduction between the two regimens could be detected. Consequently, this study confirms previous studies; with a dosing frequency of more than once daily there is a loss of part of the initial effect. $^{69}$ In this study the four times daily treated eye lost about $20 \%$ of its initial IOP reduction during the first 3 days of treatment. The total loss of effect at day 15 was $27 \%$. No similar loss of effect was observed with once daily treatment throughout the 28 days. In a previous study ${ }^{9}$ where twice daily dosing was compared with once daily, the absolute loss of IOP reduction from the third day of treatment to the 16 th was $21 \%$ in the twice daily treated eyes. The corresponding figure for the four times daily dosing eyes in the present study was $27 \%$. Thus, we can conclude that a loss of effect occurs with a higher dosing frequency than once daily but that there is little difference between twice or four times daily. From the present study it is not possible to determine the actual mechanism behind the loss of effect with frequent dosing of latanoprost. A modest desensitisation of the FP receptor is a plausible explanation but, to the best of our knowledge, a desensitisation of a receptor as a result of the frequency of the dosing has never been described. However, loss of effect with frequent dosing is well known for the nonreceptor mediated effect of nitrates. ${ }^{12}$

The secondary aim of this study was to investigate if a loss of effect for the multiple drop treatment persisted when switching to a single daily drop regimen on the assumption that the loss of effect with four daily doses had been very marked. However, this was not the case and we did not observe any change in efficacy when switching from four daily doses to one dose, which is reasonable since the final effect with four daily doses was similar to that of one daily dose. Thus, giving four daily doses causes an initially better response but that difference is lost after a few days of treatment.

After treatment termination IOP slowly increased similarly in both eyes, but never reached baseline IOP during 3 weeks of observation. Structural changes in the ciliary muscle have been reported with $\mathrm{PGF}_{20}{ }^{13}{ }^{14}$ and additional studies ${ }^{15}{ }^{16}$ suggest that latanoprost is involved in the remodelling of the extracellular matrix in the ciliary muscle. This might explain why IOP was not completely restored during the 3 weeks of follow up.
Two subjects were withdrawn because of symptoms indicating an inflammatory response in the anterior segment of the eye. One of them had a slight flare. Another 10 subjects complained of transient photophobia and in most of these eyes a minimal flare could be observed. Symptoms and signs of inflammation disappeared within a week despite continued treatment. A few cases of anterior uveitis during treatment with latanoprost have been reported, mainly in eyes with a previous history of intraocular inflammation. ${ }^{17-19}$ The present study indicates that at a dose four times the clinical dose latanoprost can induce a transient inflammatory response in some normal eyes, but in all eyes where treatment was continued this was resolved spontaneously. Marked photophobia was the main reason for withdrawal of two subjects.

In conclusion the present study confirms that with a substantial increase of the clinical dose of latanoprost there is only a short lasting small additional effect on IOP compared with the clinical once daily regimen. The result is similar to that previously observed with twice daily dosing and four daily doses cause comparable loss of effect as earlier described after two daily doses. With four daily doses about two fifths of the subjects experienced transient photophobia, and in most of these subjects a minimal flare could be observed. Symptoms and signs resolved despite continuous treatment but two subjects were withdrawn mainly because of marked photophobia.

Christina Lindén has no financial interest in Pharmacia Co; is a consultant to Pharmacia Co. Pharmacia \& Upjohn, Uppsala, Sweden, supplied coded bottles of latanoprost and vehicle.

1 Alm A, Stjernschantz J, and the Scandinavian Latanoprost Study Group. Effects on intraocular pressure and side effects of $0.005 \%$ latanoprost applied once daily, evening or morning. A comparison with timolol. Ophthalmology 1995;102:1743-52.

2 Camras CB, and the United States Latanoprost Study Group. Comparison of latanoprost and timolol in patients with ocular hypertension and glaucoma. A six-month, masked, multicenter trial in the United States. Ophthalmology 1996;103:138-47.

3 Watson P, Stjernschantz J, and the Latanoprost Study Group. A six-month, randomized, double-masked study comparing latanoprost with timolol in open-angle glaucoma and ocular hypertension. Ophthalmology 1996;103: $126-37$

4 Toris CB, Camras CB, Yablonski ME. Effects of PhXA41, a new prostaglandin $\mathrm{F}_{2 \alpha}$ analog, on aqueous humor dynamics in human eyes. Ophthalmology 1993;100:1297-304.

5 Stjernschantz J, Selén G, Sjöquist B, et al. Preclinical pharmacology of latanoprost, a phenyl-substituted $\mathrm{PGF}_{2}$ analogue. In: Samuelsson B, Ramwell PW, Paoletti R, et al, eds. Advances in prostaglandin, tromboxane, and leukotriene research. Vol 23. New York: Raven Press, 1995:513-8.

6 Nagasubramanian S, Sheth GP, Hitchings RA, et al. Nagasubramanian S, Sheth GP, Hitchings RA, et al.
Intraocular pressure-reducing effect of PhXA41 in ocular Intraocular pressure-reducing effect of PhXA41 in ocular
hypertension. Comparison of dose regimens. Ophthalmology 1993;100:1305-11.

7 Alm A, Widengård I, Kjellgren D, et al. Latanoprost administered once daily caused a maintained reduction of intraocular pressure in glaucoma patients treated concomitantly with timolol. Br $\mathscr{f}$ Ophthalmol 1995;79:12-16.

8 Lindén C, Alm A. Effects on intraocular pressure and aqueous flow of various dose regimens of latanoprost in human eyes. Acta Ophthalmol Scand 1997;75:412-5.

9 Lindén C, Alm A. Latanoprost twice daily is less effective than once daily: indication of receptor subsensitivity? Curr Eye Res 1998;17:567-72.

10 Camras CB, Schumer RA, Marsk A, et al. Intraocular pressure reduction with PhXA34, a new prostaglandin analogue, in patients with ocular hypertension. Arch analogue, in patients with
Ophthalmol 1992;110:1733-8.

11 Alm A, Villumsen J, Törnquist P, et al. Intraocular pressurereducing effect of PhXA41 in patients with increased eye reducing effect of PhXA41 in patients with increased eye
pressure. A one-month study. Ophthalmology 1993;100: pressure. 
12 Parker JO, Farrell B, Lahey KA, et al. Effect of intervals Parker JO, Farrell $\mathrm{B}$, Lahey KA, et al. Effect of intervals between doses on the development of tolerance
ide dinitrate. N Engl f Med 1987;316:1440-4.

13 Lütjen-Drecoll E, Tamm E. Morphological study of the anterior segment of cynomolgus monkey eyes following treatment with prostaglandin $\mathrm{F}_{20}$. Exp Eye Res 1988;47:761-9.

14 Tamm E, Rittig M, Lütjen-Drecoll E. Elektronmikroskopische und immunhistochemische Untersuchungen zur augendrucksenkenden Wirkung von Prostaglandin $\mathrm{F}_{20}$. Fortschr Ophthalmol 1990;87:623-9.

15 Weinreb RN, Kashiwagi K, Kashiwagi F, et al. Prostaglandins increase matrix metalloproteinase release from human ciliary smooth muscle cells. Invest Ophthalmol Vis Sci 1997; 38:2772-80.
16 Ocklind A. Effect of latanoprost on the extracellular matrix of the ciliary muscle. A study on cultured cells and tissue sections. Exp Eye Res 1998;67:179-91.

17 Fechtner RD, Khouri AS, Zimmerman TJ, et al. Anterior uveitis associated with latanoprost. Am f Ophthalmol 1998; 126:37-41.

18 Warwar RE, Bullock JD, Ballal D. Cystoid macular edema and anterior uveitis associated with latanoprost use. Experience and incidence in a retrospective review of 94 patients. Ophthalmology 1998;105:263-8.

19 Smith SL, Pruitt CA, Sine CS, et al. Latanoprost 0.005\% and anterior segment uveitis. Acta Ophthalmol Scand 1999; 77:668-72

\section{Contributors please note:}

Communications from all countries except the UK and Republic of Ireland should be sent to Professor C Hoyt, Editor, British Fournal of Ophthalmology, University of California, Department of Ophthalmology, 10 Kirkham Street, K 301, San Francisco, CA 94143-0730, USA (tel: 001415 502-6871; fax: 001415 514-1521).

Manuscripts from the UK and the Republic of Ireland should be sent to Professor Andrew Dick, UK Editor, British fournal of Ophthalmology, Division of Ophthalmology, University of Bristol, Lower Maudlin Street, Bristol BS1 2LX (tel: +44 (0) 0117 929-4496; fax: +44 (0) 117 929-4607). 